Nota / Note

\title{
CARACTERIZAÇÃO E AVALIAÇÃO DE POPULAÇÕES DE MILHO CRIOULO
}

\author{
Pedro Mário de Araújo; Luciano Lourenço Nass \\ ${ }_{2}^{1}$ Instituto Agronômico do Paraná - Rod. Celso Garcia Cid, Km 375 - C.P.481, CEP: 86001-970 - Londrina, PR \\ ${ }^{2}$ Embrapa Recursos Genéticos e Biotecnologia - C.P. 02372 - CEP: 70770-900 - Brasília, DF. \\ *Autor correspondente<llnass@cenargen.embrapa.br>
}

\begin{abstract}
RESUMO: A escolha do germoplasma é parte fundamental e decisiva para o sucesso de qualquer programa de melhoramento de plantas. Os objetivos deste trabalho foram caracterizar e avaliar o potencial genético de populações crioulas de milho (Zea mays L.) mantidas pelo IAPAR para fins de melhoramento. É apresentada uma caracterização de 25 populações crioulas de milho com relação ao tipo de endosperma e coloração dos grãos. Foram conduzidos ensaios em blocos ao acaso com duas repetições em três locais (Londrina-PR, Ponta Grossa-PR e Anhembi-SP). As populações crioulas mais promissoras para fins de melhoramento com ênfase na produção de grãos, na média dos três locais, foram GI156 (Cayano Sobrália) e GI045 (Tupy Pyta Sopé). A produtividade dessas populações correspondeu, respectivamente, a $86,9 \%$ e $84,6 \%$ em relação ao híbrido comercial AG122, sendo de mesma magnitude das variedades adaptadas BR-105 e BR-106.

Palavras-chave: Zea mays, germoplasma, raças locais
\end{abstract}

\section{CHARACTERIZATION AND EVALUATION OF MAIZE LANDRACES}

\begin{abstract}
The choice of germplasm plays an important role in any plant breeding program. The goals of this paper were to characterize and to evaluate the genetic potential of IAPAR's maize (Zea mays L.) landraces for breeding purposes. Characterization of 25 landraces of maize for endosperm type and kernel color is shown. In 1998/99, experiments using randomized complete block designs with two replications were carried out in three locations of Brazil (Londrina-PR, Ponta Grossa-PR, and Anhembi-SP). For grain yield, the most promising landraces were GI156 (Cayano Sobrália) and GI045 (Tupy Pyta Sopé). Their performances for grain yield represent $86.9 \%$ and $84.6 \%$ of the hybrid $A G 122$ yield, respectively, and were of the same magnitude of the adapted varieties (BR-105 and BR-106).

Key words: Zea mays, germplasm, autochthon
\end{abstract}

\section{INTRODUÇÃO}

A diversidade genética existente no milho permite o seu cultivo nos mais diversos ambientes. $O$ milho é cultivado desde a latitude $58^{\circ} \mathrm{N}$ até $40^{\circ} \mathrm{S}$, desenvolvendo-se desde o nível do mar até $3.800 \mathrm{~m}$ de altitude (Hallauer \& Miranda Filho, 1988). Além disso, o milho é a espécie vegetal geneticamente mais estudada e, conseqüentemente, a herança de inúmeros caracteres e o seu genoma são bem conhecidos. A importância econômica, a sua estrutura genética, o número de cromossomos, o tipo de reprodução, a facilidade para realizar polinizações manuais e a possibilidade de gerar diferentes tipos de progênies, são fatores que muito contribuíram no sentido de tornar este cereal um modelo para as espécies alógamas (Nass \& Paterniani, 2000).

O germoplasma de milho é constituído por raças crioulas (locais), populações adaptadas e materiais exóticos introduzidos, sendo caracterizado por uma ampla variabilidade genética. A demanda constatada junto aos fitomelhoradores por conhecimentos mais abrangentes, tanto qualitativos como quantitativos, sobre o germoplasma de milho no Brasil é cada vez mais intensa
(Nass et al., 1993), o que pode ser verificado pela grande competitividade existente no mercado pelo desenvolvimento de novos cultivares.

A escolha do germoplasma é parte fundamental e decisiva para qualquer programa de melhoramento de plantas, quer seja para o desenvolvimento de variedades, para utilização em híbridos ou para estudos básicos, podendo inclusive influir significativamente no sucesso ou no fracasso da seleção.

As populações crioulas, também conhecidas como raças locais ou landraces, são materiais importantes para o melhoramento pelo elevado potencial de adaptação que apresentam para condições ambientais específicas (Paterniani et al., 2000) . De maneira geral, as populações crioulas são menos produtivas que os cultivares comerciais. Entretanto, essas populações são importantes por constituírem fonte de variabilidade genética que podem ser exploradas na busca por genes tolerantes e/ou resistentes aos fatores bióticos e abióticos.

Os melhoristas têm procurado ampliar a variabilidade genética nos seus programas de melhoramento, principalmente após a catástrofe ocorrida 
em 1970 nos Estados Unidos, em função de uma epidemia causada pela ocorrência de Helminthosporium maydis. O intercâmbio de linhagens elites entre programas distintos de melhoramento tem sido a maneira usual para ampliação da variabilidade genética, porém, o germoplasma existente nos centros de origem, nos centros de diversificação e nos bancos de germoplasma, ainda são pouco explorados (Sprague, 1980). No levantamento realizado entre instituições públicas e privadas no Brasil, Nass et al. (1993) constataram que a utilização regular dos acessos disponíveis nos bancos de germoplasma é baixa entre os melhoristas de milho. A falta de descrição adequada das coleções de germoplasma e a falta de informações desejadas pelos melhoristas estão entre as principais causas da baixa utilização dos bancos de germoplasma (Paterniani et al., 2000).

Os trabalhos de melhoramento genético de milho do Instituto Agronômico do Paraná (IAPAR) têm como objetivo o desenvolvimento de cultivares comerciais principalmente para o Estado do Paraná. Paralelamente, os pesquisadores têm conduzido atividades de coletas junto aos agricultores com a finalidade de resgatar populações crioulas (locais), para posterior utilização em programas de melhoramento. Essas populações encontram-se armazenadas em câmaras frias e secas sob condições controladas. Uma análise criteriosa do programa do IAPAR identificou a necessidade de realizar uma avaliação agronômica mais consistente das populações crioulas de milho, uma vez que essas populações podem apresentar genes de interesse para os atuais programas de melhoramento genético do país, haja vista o alto poder de adaptação desse germoplasma.

Os objetivos deste trabalho foram caracterizar as populações crioulas de milho mantidas pelo banco de germoplasma do IAPAR quanto ao tipo de endosperma e coloração dos grãos, e avaliar o potencial genético per se das populações, identificando fontes de germoplasma promissoras para utilização em programas de melhoramento.

\section{MATERIAL E MÉTODOS}

Amostras representativas de 25 populações crioulas de milho (Tabela 1) foram multiplicadas no período de safrinha de 1998, no município de Anhembi-SP. Esta multiplicação foi necessária para aumentar a quantidade de sementes de cada população e uniformizar o poder germinativo em função dos ensaios de avaliação subseqüentes. Algumas populações apresentaram elevada suscetibilidade às doenças foliares, entretanto esse fator não foi limitante para a obtenção de quantidade suficiente de sementes das populações sob estudo.

No ano agrícola 1998/99 foram realizados os ensaios para observação do potencial per se das populações. Os ensaios foram constituídos por 30 tratamentos, sendo que além das 25 populações crioulas foram incluídas duas populações introduzidas do CIMMYT (GI048 e GI133), duas variedades adaptadas (BR-105 e BR-106) e um híbrido duplo comercial (AG 122). Foram realizados experimentos em blocos casualizados com duas repetições em três ambientes:

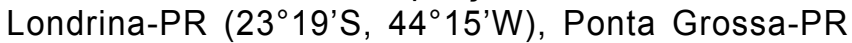

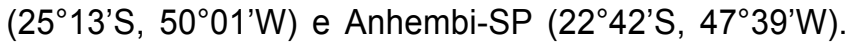
Este último foi escolhido por representar um ambiente desfavorável às populações com relação ao clima, tipo de solo e pela forte pressão de seleção para as principais doenças foliares da cultura do milho. As parcelas foram constituídas de duas linhas de $5 \mathrm{~m}$, com espaçamento entre linhas de $0,90 \mathrm{~m}$, com cinco plantas por metro. Foram usadas adubações básicas de manutenção em todos os ambientes de acordo com as análises de solo (300 kg ha-1 da fórmula 4-30-10 em Londrina e Ponta Grossa; $250 \mathrm{~kg} \mathrm{ha}^{-1}$ da fórmula 5-25-25 em Anhembi). Foram realizadas adubações de cobertura em todos os locais fornecendo um total de $40 \mathrm{~kg} \mathrm{ha}^{-1}$ de $\mathrm{N}$.

Em todos os ensaios foram avaliadas as seguintes características: altura da planta e da espiga, florescimento feminino, prolificidade e produção de grãos. A posição relativa da espiga foi calculada pelo quociente entre altura de inserção da espiga e altura da planta. Em Londrina não foram obtidos dados de altura da planta e espiga e em Anhembi não foi considerado o florescimento feminino.

\section{RESULTADOS E DISCUSSÃO}

Com base na multiplicação de sementes conduzida no município de Anhembi-SP, foi realizada uma caracterização quanto ao tipo e coloração de grãos de cada população (Tabela 1). Essa caracterização evidenciou uma ampla variabilidade com relação a esses dois aspectos, sendo úteis no sentido de direcionar futuros cruzamentos dessas com outras populações de milho.

Nos três ambientes foram observadas diferenças entre os tratamentos (dados não apresentados), evidenciando ampla variabilidade genética para produção de grãos. Em Ponta Grossa foi obtida a maior produtividade média $\left(7.004 \mathrm{~kg} \mathrm{ha}^{-1}\right)$ e o menor coeficiente de variação experimental ( $\mathrm{CVe}=8,9 \%)$. Os coeficientes de variação experimental dos demais ensaios também foram considerados aceitáveis para a experimentação de campo na cultura do milho.

Considerando os ambientes, as médias dos caracteres avaliados foram: florescimento feminino $=76$ dias, altura da planta $=260 \mathrm{~cm}$, altura de inserção da espiga $=161 \mathrm{~cm}$, posição relativa da espiga $=0,60 \mathrm{e}$ prolificidade $=1,0$ (Tabela 2 ). Com relação ao desempenho médio nos três ambientes, este conjunto de populações apresentou um porte de planta elevado; a mesma tendência foi observada para altura de inserção da espiga. Esse grupo de populações mostrou-se, em média, tardio com relação ao florescimento feminino, característica essa predominante nas populações autóctones existentes no Brasil. 
Tabela 1 - Identificação, nome comum, origem e caracterização das populações crioulas de milho do IAPAR (GI) para cor e tipo de endosperma.

\begin{tabular}{|c|c|c|c|}
\hline $\mathrm{Gl}^{*}$ & Nome Comum & Cor do grão & Tipo do endosperma \\
\hline GI002 & Amarillo Opaco Amiláceo ${ }^{1}$ & Amarelo gema & Amiláceo \\
\hline GI006 & Azteca Lupionópolis ${ }^{2}$ & Amarelo e poucos avermelhados & Dente longo \\
\hline GI008 & Azteca Nova Esperança ${ }^{3}$ & Amarelo e poucos a vermelhados & Dente longo \\
\hline GI018 & Cravo $\mathrm{N}^{0} \cdot 1^{4}$ & 2/3 Amarelo claro, 1/3 Amarelo avermelhado & Dente longo e fino \\
\hline GI036 & Roxo Azteca ${ }^{4}$ & Roxo com $1 / 4$ de amarelo & Dente largo \\
\hline GI041 & Sem identificação ${ }^{4}$ & Amarelo com alguns alaranjado & Dente largo \\
\hline GI045 & Tupy Pyta Sopé ${ }^{1}$ & Alaranjado & Semidente \\
\hline GI049 & Palmeira ${ }^{4}$ & Amarelo & Semidente, largo \\
\hline GI088 & RGS \|\|$^{5}$ & Amare lo pálido & Dente meio longo \\
\hline Gl101 & Cristal Paraguay ${ }^{1}$ & Branco & Duro e semiduro \\
\hline Gl104 & Pérola ${ }^{4}$ & Branco & Duro \\
\hline Gl105 & Tupy Moroti ${ }^{1}$ & Branco opaco & Duro e miúdo \\
\hline GI135 & Milho Caigang 6 & Branco, amarelo, roxo e avermelhados & Predomina tipo dente \\
\hline GI140 & Astequinha Ortigueira ${ }^{7}$ & Amarelo-alaranjado e alguns avermelhado & Dente longo e chato \\
\hline GI148 & General $^{9}$ & Amarelo & Dente longo \\
\hline Gl149 & Linha Paraná9 & Amarelo & Dente \\
\hline GI150 & Cinquentinha ${ }^{9}$ & Branco & Semiduro \\
\hline Gl151 & Azteca baixo ${ }^{9}$ & Amarelo & Dente \\
\hline GI152 & Amare lão ${ }^{9}$ & Amarelo intenso & Dente \\
\hline Gl153 & Macaco $^{9}$ & Amarelo com $1 / 5$ avermelhado & Dente chato \\
\hline GI154 & Tabuinha9 $^{9}$ & Amarelo & Dente largo e chato \\
\hline Gl155 & Dente de Rato ${ }^{9}$ & Amarelo e amarelo-alaranjado & Dente e meio dente \\
\hline GI156 & Cayano Sobrália ${ }^{9}$ & Amarelo & Dente \\
\hline Gl157 & Azteca branco ${ }^{9}$ & Branco & Dente longo \\
\hline GI158 & Antigo Maya ${ }^{9}$ & Amarelo com $1 / 3$ meio roxo & Dente \\
\hline
\end{tabular}


${ }^{6}$ Res. Indígena de Tamarana - PR; ${ }^{7}$ Ortigueira - PR; ${ }^{8}$ Sto. Antônio das Missões - RS; ${ }^{9}$ ASPTA, Mangueirinha - PR.

Em Londrina-PR a variedade BR-106 apresentou a maior produtividade (Tabela 3). Deve-se ressaltar 0 excelente desempenho das populações crioulas neste ensaio, sendo que seis populações (GI045, GI156, GI158, GI140, GI149 e GI036) não diferiram da variedade BR-106. Em média, o florescimento foi de 72 dias, com intervalo de variação entre 62 (GI048) a 78 dias (GI105).

Em Ponta Grossa-PR, a produtividade média $\left(7.004 \mathrm{~kg} \mathrm{ha}^{-1}\right)$ foi maior que a constatada em Londrina $\left(5.532 \mathrm{~kg} \mathrm{ha}^{-1}\right)$. Verifica-se o elevado potencial de produção das populações crioulas, haja vista que em valores médios absolutos oito populações superaram a variedade $B R-105$ e 11 populações foram mais produtivas que a variedade $B R-106$. A maior produtividade nesse ambiente foi constatada em Gl156 (9.121 kg ha-1). Além disso, essa população apresentou comportamento equivalente às variedades adaptadas BR-105 e BR-106 para os demais caracteres avaliados. A média geral do ensaio para altura da planta foi $260 \mathrm{~cm}$ e para altura de inserção da espiga $155 \mathrm{~cm}$, sendo esses valores altos se comparados aos materiais comerciais atualmente disponíveis. Porém, como são populações pouco trabalhadas em termos de melhoramento, espera-se que com o emprego de seleção recorrente para redução destas características (Regitano Neto et al., 1997), as populações apresentem melhor desempenho quanto ao porte das plantas.

Em Anhembi-SP a produtividade média ( $3.292 \mathrm{~kg}$ $\mathrm{ha}^{-1}$ ) foi a menor entre os ambientes (Tabela 3). Este resultado era esperado, uma vez que esse local apresenta fatores limitantes em termos de condições edafoclimáticas e de incidência de doenças foliares. A média geral do experimento para o caráter altura da planta foi $261 \mathrm{~cm} \mathrm{e}$ para altura de inserção da espiga $167 \mathrm{~cm}$ (Tabela 2).

As médias nos três ambientes para produção de grãos, a posição relativa de cada tratamento por experimento e a porcentagem em relação ao híbrido AG122, utilizado como testemunha são apresentadas na Tabela 3. Um grupo de populações apresentou produtividade semelhante as duas populações adaptadas. As populações GI156 e GI045 apresentaram produtividade média de $6.908 \mathrm{~kg} \mathrm{ha}^{-1}$ e $6.723 \mathrm{~kg} \mathrm{ha}^{-1}$, 
Tabela 2 - Médias das populações crioulas de milho avaliadas em três ambientes $\left(L_{1}\right.$ - Londrina; $L_{2}-P_{0}$ ta $G r o s s a ; L_{3}-$ Anhembi).

\begin{tabular}{|c|c|c|c|c|c|c|c|c|c|c|c|}
\hline \multirow{2}{*}{ Pop(s) } & \multicolumn{2}{|c|}{$\mathrm{FF}^{\#}$} & \multicolumn{2}{|c|}{ AP } & \multicolumn{2}{|c|}{$A E$} & \multicolumn{2}{|c|}{ PRE } & \multicolumn{3}{|c|}{ PRO } \\
\hline & $\mathrm{L}_{1}$ & $\mathrm{~L}_{2}$ & $\mathrm{~L}_{2}$ & $\mathrm{~L}_{3}$ & $\mathrm{~L}_{2}$ & $\mathrm{~L}_{3}$ & $\mathrm{~L}_{2}$ & $\mathrm{~L}_{3}$ & $\mathrm{~L}_{1}$ & $\mathrm{~L}_{2}$ & $\mathrm{~L}_{3}$ \\
\hline $\mathrm{Gl} 002$ & 76 & 90 & 263 & 265 & 158 & 177 & 0,60 & 0,67 & 0,8 & 0,7 & 0,8 \\
\hline G1006 & 76 & 85 & 278 & 266 & 183 & 170 & 0,66 & 0,64 & 0,9 & 0,9 & 1,0 \\
\hline GI008 & 76 & 88 & 285 & 284 & 175 & 196 & 0,62 & 0,69 & 1,0 & 1,0 & 1,1 \\
\hline Gl018 & 75 & 81 & 268 & 269 & 173 & 188 & 0,65 & 0,70 & 1,0 & 1,1 & 1,1 \\
\hline GI036 & 75 & 84 & 283 & 292 & 175 & 203 & 0,62 & 0,70 & 1,0 & 0,8 & 1,1 \\
\hline GI041 & 72 & 75 & 263 & 263 & 150 & 165 & 0,57 & 0,63 & 1,0 & 1,1 & 1,1 \\
\hline GI045 & 75 & 84 & 265 & 264 & 150 & 178 & 0,56 & 0,67 & 1,1 & 1,0 & 1,1 \\
\hline $\mathrm{Gl} 048^{\lambda}$ & 62 & 74 & 205 & 228 & 128 & 123 & 0,62 & 0,54 & 0,9 & 0,9 & 0,9 \\
\hline GI049 & 75 & 79 & 253 & 261 & 160 & 162 & 0,63 & 0,62 & 1,0 & 1,0 & 1,2 \\
\hline G1088 & 70 & 75 & 238 & 228 & 150 & 141 & 0,63 & 0,62 & 0,9 & 1,0 & 1,2 \\
\hline Gl101 & 75 & 89 & 263 & 258 & 185 & 169 & 0,70 & 0,66 & 0,8 & 0,9 & 0,6 \\
\hline Gl104 & 71 & 76 & 268 & 243 & 150 & 152 & 0,56 & 0,62 & 1,1 & 1,0 & 1,1 \\
\hline Gl105 & 78 & 88 & 278 & 269 & 170 & 178 & 0,61 & 0,66 & 1,1 & 0,9 & 0,9 \\
\hline $\mathrm{Gl} 133^{\lambda}$ & 65 & 71 & 183 & 188 & 85 & 103 & 0,47 & 0,55 & 1,1 & 0,9 & 1,3 \\
\hline Gl135 & 75 & 89 & 300 & 301 & 193 & 213 & 0,64 & 0,71 & 0,8 & 1,0 & 0,9 \\
\hline Gl140 & 75 & 84 & 255 & 272 & 155 & 172 & 0,61 & 0,63 & 1,1 & 1,0 & 1,3 \\
\hline Gl148 & 75 & 85 & 273 & 273 & 178 & 174 & 0,65 & 0,64 & 1,0 & 1,0 & 1,2 \\
\hline Gl149 & 75 & 82 & 295 & 282 & 173 & 193 & 0,58 & 0,68 & 1,1 & 0,9 & 0,8 \\
\hline GI150 & 68 & 72 & 243 & 227 & 138 & 127 & 0,57 & 0,56 & 0,9 & 1,1 & 1,2 \\
\hline Gl151 & 67 & 73 & 253 & 257 & 145 & 158 & 0,57 & 0,61 & 1,0 & 1,0 & 1,02 \\
\hline GI152 & 76 & 84 & 265 & 293 & 150 & 197 & 0,57 & 0,67 & 1,0 & 0,9 & 1,0 \\
\hline GI153 & 70 & 78 & 260 & 263 & 138 & 160 & 0,53 & 0,61 & 1,0 & 1,0 & 1,1 \\
\hline GI154 & 69 & 76 & 238 & 258 & 135 & 164 & 0,56 & 0,64 & 0,9 & 1,0 & 0,9 \\
\hline GI155 & 72 & 78 & 268 & 273 & 168 & 186 & 0,62 & 0,68 & 1,1 & 1,0 & 1,3 \\
\hline GI156 & 71 & 77 & 243 & 243 & 130 & 149 & 0,54 & 0,61 & 1,2 & 1,1 & 1,1 \\
\hline Gl157 & 76 & 91 & 320 & 303 & 200 & 198 & 0,62 & 0,65 & 0,9 & 0,9 & 0,8 \\
\hline GI158 & 75 & 87 & 273 & 285 & 170 & 193 & 0,62 & 0,68 & 1,1 & 1,0 & 1,0 \\
\hline BR105* & 67 & 74 & 233 & 248 & 130 & 140 & 0,56 & 0,56 & 1,2 & 1,3 & 1,2 \\
\hline BR106* & 70 & 83 & 235 & 238 & 130 & 138 & 0,55 & 0,58 & 1,5 & 1,3 & 1,2 \\
\hline AG122" & 66 & 69 & 240 & 231 & 133 & 136 & 0,55 & 0,59 & 1,0 & 1,0 & 1,1 \\
\hline Média & 72 & 81 & 260 & 261 & 155 & 167 & 0,60 & 0,60 & 1,0 & 1,0 & 1,1 \\
\hline
\end{tabular}

\#FF: Florescimento Feminino (dias); AP: Altura da Planta (cm); AE: Altura de inserção da espiga (cm); PRE: Posição Relativa Espiga; PRO: Prolificidade

${ }^{\lambda}$ População introduzida do CIMMYT; *População adaptada; \#Testemunha

respectivamente. Em números absolutos estes valores são superiores aos obtidos por BR-106 e BR-105, que foram de $6.661 \mathrm{~kg} \mathrm{ha}^{-1}$ e $6.301 \mathrm{~kg} \mathrm{ha}^{-1}$, respectivamente. Já as populações GI149, GI041, GI158, GI049, GI036, GI148 e GI140, também apresentaram produtividade próxima da obtida pelas duas variedades comerciais.

Comparando-se com o híbrido AG122, as populações Gl156, GI045, GI149, GI041, GI158, GI049, GI036, GI148 e GI140 apresentaram valores percentuais entre $86,9 \%$ e $75,5 \%$, o que pode ser considerado bom em se tratando de populações e, principalmente, de populações crioulas que não foram submetidas a qualquer processo de seleção. Outro grupo apresentou produtividade entre $70,3 \%$ e $65,2 \%$ em relação ao híbrido comercial, podendo ser útil para fins de melhoramento caso apresente outras características desejáveis como porte, ciclo, heterose e resistência ou tolerância aos estresses bióticos e abióticos.

As populações crioulas que apresentaram desempenho inferior a 50\% em relação à testemunha têm potencial muito limitado para serem aproveitadas em programas de melhoramento. A busca por genótipos superiores em produtividade, resistência a pragas e doenças, tolerância aos estresses ambientais ou de melhor qualidade nutricional, é bastante árdua, competitiva e de custo elevado (Nass \& Paterniani, 2000). Desta forma, muitos melhoristas evitam trabalhar com populações crioulas disponíveis nos bancos de germoplasma. A única justificativa para investimento em termos de melhoramento nas populações com desempenho inferior a $50 \%$ seria a presença de genes específicos de interesse, especialmente com relação aos 
Tabela 3 - Produtividade $\left(\mathrm{PG}^{+}\right.$em kg ha-1) média por local, média geral, respectivas posições relativas $(\mathrm{P})$ e porcentagem em relação ao híbrido AG 122 (\%), das populações crioulas de milho em três ambientes (1998/99).

\begin{tabular}{|c|c|c|c|c|c|c|c|c|c|}
\hline \multirow{2}{*}{ Pop(s) } & \multicolumn{2}{|c|}{ Lond rina-PR } & \multicolumn{2}{|c|}{ Ponta Grossa-PR } & \multicolumn{2}{|c|}{ Anhembi-SP } & \multicolumn{2}{|c|}{ Média Geral } & \multirow{2}{*}{$\begin{array}{c}\mathrm{AG} 122 \\
\%\end{array}$} \\
\hline & $P G$ & $P$ & $P G$ & $P$ & $P G$ & $P$ & $P G$ & $P$ & \\
\hline$\overline{A G 122^{\#}}$ & 7746 & 2 & 10258 & 1 & 5830 & 1 & 7945 & 1 & 100,0 \\
\hline Gl156 & 7376 & 4 & 9121 & 2 & 4226 & 7 & 6908 & 2 & 86,9 \\
\hline GI045 & 7408 & 3 & 7786 & 8 & 4976 & 2 & 6723 & 3 & 84,6 \\
\hline BR106* & 8134 & 1 & 7301 & 14 & 4549 & 3 & 6661 & 4 & 83,8 \\
\hline BR105* & 6810 & 7 & 7741 & 10 & 4351 & 6 & 6301 & 5 & 79,3 \\
\hline Gl149 & 6745 & 8 & 8342 & 6 & 3653 & 13 & 6247 & 6 & 78,6 \\
\hline GI04 1 & 6112 & 11 & 8611 & 3 & 3764 & 10 & 6162 & 7 & 77,6 \\
\hline Gl158 & 7323 & 5 & 7112 & 17 & 3892 & 9 & 6109 & 8 & 76,9 \\
\hline GI049 & 5949 & 14 & 7844 & 7 & 4396 & 5 & 6063 & 9 & 76,3 \\
\hline GI036 & 6443 & 9 & 7171 & 16 & 4424 & 4 & 6013 & 10 & 75,7 \\
\hline Gl148 & 6090 & 12 & 8377 & 5 & 3528 & 15 & 5998 & 11 & 75,5 \\
\hline Gl140 & 6965 & 6 & 6841 & 20 & 4181 & 8 & 5996 & 12 & 75,5 \\
\hline Gl018 & 4872 & 22 & 8464 & 4 & 3431 & 17 & 5589 & 13 & 70,3 \\
\hline Gl153 & 5782 & 17 & 7781 & 9 & 3149 & 20 & 5571 & 14 & 70,1 \\
\hline GI151 & 5527 & 19 & 7411 & 12 & 3722 & 12 & 5553 & 15 & 69,9 \\
\hline Gl155 & 5779 & 18 & 7405 & 13 & 3476 & 16 & 5553 & 16 & 69,9 \\
\hline GI006 & 5847 & 16 & 6898 & 19 & 3604 & 14 & 5450 & 17 & 68,6 \\
\hline Gl152 & 6074 & 13 & 6323 & 22 & 3753 & 11 & 5383 & 18 & 67,7 \\
\hline Gl104 & 5919 & 15 & 6620 & 21 & 3330 & 19 & 5290 & 19 & 66,6 \\
\hline GI008 & 6340 & 10 & 5770 & 26 & 3420 & 18 & 5177 & 20 & 65,2 \\
\hline Gl157 & 5272 & 20 & 7057 & 18 & 2601 & 21 & 4977 & 21 & 62,6 \\
\hline Gl154 & 4775 & 23 & 7497 & 11 & 2576 & 22 & 4949 & 22 & 62,3 \\
\hline $\mathrm{Gl} 133^{\lambda}$ & 5013 & 21 & 6075 & 25 & 2545 & 23 & 4544 & 23 & 57,2 \\
\hline Gl150 & 4039 & 25 & 7263 & 15 & 2118 & 24 & 4473 & 24 & 56,3 \\
\hline GI088 & 4051 & 24 & 6147 & 24 & 1708 & 27 & 3969 & 25 & 50,0 \\
\hline Gl105 & 3902 & 26 & 5456 & 27 & 2090 & 25 & 3816 & 26 & 48,0 \\
\hline Gl135 & 3240 & 27 & 6274 & 23 & 1872 & 26 & 3795 & 27 & 47,8 \\
\hline $\mathrm{Gl} 048^{\lambda}$ & 2700 & 28 & 4221 & 28 & 1431 & 28 & 2784 & 28 & 35,0 \\
\hline Gl101 & 1722 & 30 & 3785 & 29 & 948 & 30 & 2152 & 29 & 27,1 \\
\hline GI002 & 2010 & 29 & 3173 & 30 & 1226 & 29 & 2136 & 30 & 26,9 \\
\hline Média & 5532 & - & 7004 & - & 3292 & - & 5276 & - & - \\
\hline
\end{tabular}

'População introduzida do CIMMYT; *População adaptada; "Testemunha; 'Dados corrigidos para 14,5\% de umidade.

estresses bióticos e abióticos importantes na cultura do milho. Nesse caso, o uso de programas de retrocruzamento seria o mais apropriado, na tentativa de incluir tais genes em populações adaptadas de maior potencial produtivo. Além disso, o uso da biotecnologia poderá ser ferramenta útil na identificação desses genes.

\section{REFERÊNCIAS BIBLIOGRÁFICAS}

HALLAUER, A.R.; MIRANDA FILHO, J.B. Quantitative genetics in maize breeding. Ames: lowa University Press, 1988. 468p.

NASS, L.L.; PATERNIANI, E. Pre-breeding: a link between genetic resources and maize breeding. Scientia Agricola, v.57, p.581-587, 2000.
NASS, L.L.; PELLICANO, I.J.; VALOIS, A.C.C. Utilization of genetic resources for maize and soybean breeding in Brazil. Brazilian Journal of Genetics, v.16, p.983-988, 1993.

PATERNIANI, E.; NASS, L.L.; SANTOS, M.X. O valor dos recursos genéticos de milho para o Brasil: uma abordagem histórica da utilização do germoplasma. In: UDRY, C.W.; DUARTE, W. (Org.) Uma história brasileira do milho: o valor dos recursos genéticos. Brasília: Paralelo 15, 2000. p.11-41.

REGITANO NETO, A.; NASS, L.L.; MIRANDA FILHO, J.B. Potential of twenty exotic germplasms to improve Brazilian maize architecture. Brazilian Journal of Genetics, v.20, p.691-696, 1997.

SPRAGUE, G.F. Germplasm resources of plants: their preservation and use. Annual Review of Phytopathology, v.18, p.147-165, 1980.

$\overline{\text { Recebido em } 18.05 .01}$ 